\title{
Remote sensing techniques for tracking changes caused by illegal gold mining in Madre de Dios, Peru
}

\begin{abstract}
Illegal extraction of gold has grown to be a problem in many countries, causing the degradation of the environment. The main purpose of this paper is to investigate changes in tree cover and surface pollution. The development of a mine site has been observed and analysed with images acquired from Landsat and the Sentinel missions. The results of the study showed changes in the state of the environment, strongly suggesting the possibility of ongoing pyrite weathering processes and the transportation of clay materials down watercourses, which can cause not only the further deterioration of the environment but also slow down the natural regeneration of the forest. In addition, research has found disturbing changes in vegetation, showing a loss of tree cover in the Amazon Rainforest as high as $17 \%$. The validity of using remote sensing methods to observe the development of individual mining sites and their characteristics was confirmed.
\end{abstract}

Keywords

Environmental monitoring $\bullet$ geospatial analysis $•$ South America $\bullet$ remote sensing $\cdot$ Peru

(c) University of Warsaw - Faculty of Geography and Regional Studies
Katarzyna Adamek $\mathbb{C}^{1}$, Michał Lupa $\mathbb{C}^{1}$, Mateusz Zawadzki $\mathbb{C}^{2}$

'Department of Geoinformatics and Applied Computer Science, Faculty of Geology, Geophysics and Environmental Protection, AGH University of Science and Technology, Kraków, Poland e-mail: kadamek@agh.edu.pl e-mail:mlupa@agh.edu.pl

${ }^{2}$ Institute of Socio-Economic Geography and Spatia Management, Department of Cartography and Geomatics, The Faculty of Earth Sciences and Spatial Management, Maria Curie-Sklodowska University, Lublin, Poland

e-mail: mateusz.zawadzki@umcs.pl

Received: 18 December 2019

Accepted: 28 June 2020

\section{Introduction}

Nowadays, South America is facing a gold rush due to the rising gold prices of recent decades (ACM 2014). One of the biggest problems related to this crisis is the lack of information about the scale of damage and pollution caused by illegal and informal gold mining. This makes official processes of remediation, safety management and the formalization of mine sites much more difficult (Heck 2014).

As the problem is growing and mostly occurs in remote areas, the usage of remote sensing to detect illegal mine sites is attracting more attention. One example is a Colombian government project that aims to use remote sensing as a tool for the detection of unwanted alluvial gold exploitation (UNODC 2016). Colombia is situated next to Peru in a group of countries struggling with this phenomenon. Remote sensing in the region should be implemented as part of a preventative system. Satellite images are usually used as a source of data for observing deforestation in the areas surrounding mine sites (Swenson et al. 2011; WRI 2018). Since pollution associated with artisanal gold mining is a threat to all living beings and human health, thorough research should be carried out. Currently, Peru produces more gold - both legal and illegal - than any other country in South America. In 2013, illegal gold mining was reported in 21 of the 26 provinces in the country. Moreover, in Madre de Dios Province, $90 \%$ of gold (up to 18 tonnes of gold per year) is mined illegally (Wagner 2016). In this region, miners have also entered the Tambopata National Reserve, an area of globally unique diversity and containing many endemic species that are listed by the International Union for Conservation of Nature and Natural Resources. Large areas of Madre de Dios are covered with tropical rainforests and are home to many indigenous tribes (Forest 2012). Both illegal and informal mining can, and usually does, lead to serious environmental problems (Butler 2012). Many problems are caused by factors such as the geology of the mine site, the climate, hydrology, the use of heavy machinery, dangerous substances, etc.

The drainage of acids, related to the weathering of sulphide minerals like pyrite, can lead to a rise in the acidity of water in surrounding areas along with heavy metal contamination (Viljo et al. 2003). The issue of the remote sensing of heavy metals in the environment has been raised in many pieces of research, including that of Zagajewski (2000). However, contamination with mercury is considered to be the biggest threat to local populations. It has been estimated that every year about 30 tonnes of mercury are dumped into the waters of the Amazon region (Wagner 2016). Other calculations show that more than 120 tonnes of mercury are used every year in artisanal mining in Peru. In 2009, it was estimated that 130 tonnes of mercury are imported annually and about $95 \%$ of this is used in informal or illegal gold mining (Swenson et al. 2011). Mercury is commonly used in the amalgamation process of gold mining. To recover gold, amalgam is burnt in order to burn off the mercury, which is released into the air, soil and water as a result. Very often mercury is also carelessly dumped into the environment (Heck 2014). The use of remote sensing methods to observe the state of the environment, alerted by mining operations or other human actions, is becoming an important tool as it is considered to be time- and cost-efficient. In recent years there has been growing interest in the use of satellite data, as more and more data is available at no cost and is easy to order. Various approaches 


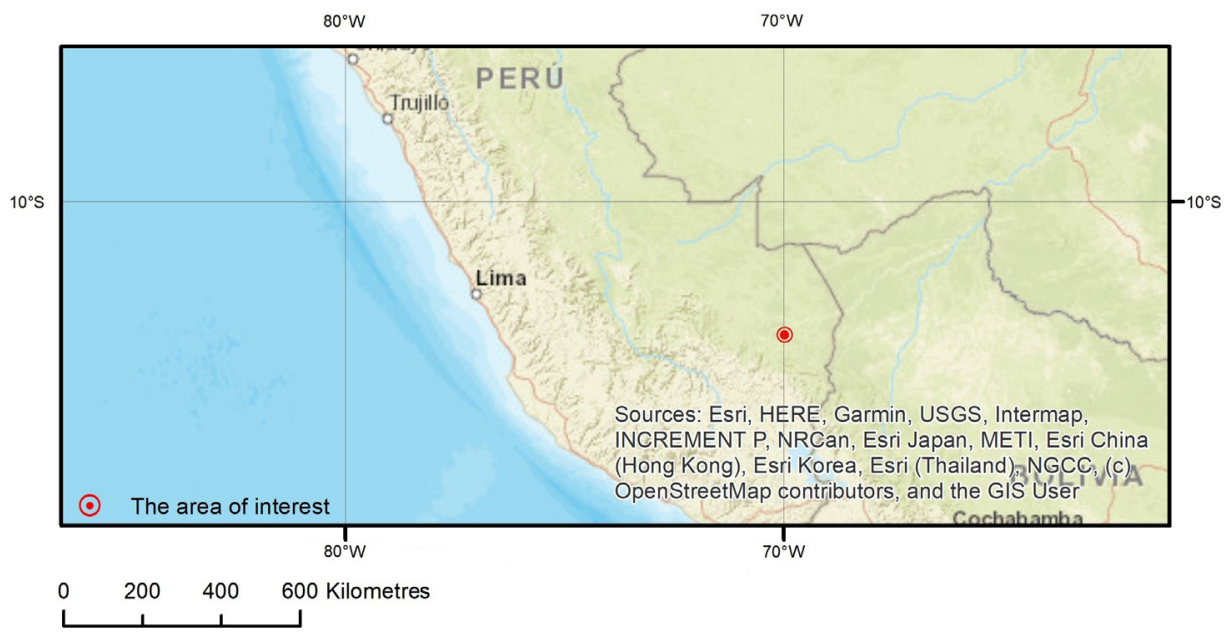

Figure 1. Location of the area of interest Source: Own elaboration

have been proposed in recent years. One example is the Litov dump in the Czech Republic, where jarosite/oxy-hydroxies were mapped, suggesting the usability of data delivered by Sentinel-2 to observe Acid Mine Drainage (AMD) (Kopačková 2019). Also, Seifi et al. (2019) reach the conclusion that Sentinel-2 data have the potential to be used in observing AMD-associated products. In other research, Lobo et al. (2017) present the usefulness of the data provided by Sentinel-2 in terms of obtaining information on mine sites such as their scale. A broad discussion on the use of remote sensing to observe the impact of mining on the environment has also been presented by Chavrel (2016).

Deforestation is another issue threatening the Amazon Rainforest, with an estimated area loss of $1,680 \mathrm{~km}^{2}$ between 2001 and 2013 (Wagner 2016). In September 2012 in the Madre de Dios region, deforestation reached the level of 50 thousand hectares. A number of studies using remote sensing data have been carried out in order to track deforestation (e.g. Müller 2015; Olofsson et al. 2016; Viña, Echavarria \& Rundquist 2004). Furthermore, very detailed research using satellite data for tracking forest changes was carried out by Asner \& Tupayachi (2016). Huge damage is also done to soils and general morphology. Illegal and informal mining in this region involves the transport of large volumes of material (mostly gravel); this damages the natural vegetation and soils, thereby causing erosion and the reduced possibility of re-establishing natural plant coverage. This also leads to the destruction of the most fertile agricultural lands in the region. Another problem is the increase of suspended solids in the watercourses due to the washing out of clay minerals and other material from bedrocks. This causes a higher level of turbidity in river streams which affects aquatic life, changes the morphology of the banks and riverbeds, and generally reduces water quality (Heck 2014).

\section{Geology background}

Madre de Dios Province (Fig. 1) is located within the Amazonian Craton (Umberto et al. 2016). According to INGEMMET (2011), the whole area of research is covered with quaternary alluvial deposits, mostly Pleistocene. Holocene sediments are located along bigger rivers like the Madre de Dios (Rio Madre de Dios).

The Madre de Dios alluvial plain consists mostly of gravels, sands, clays, and silts. The thickness of the sediment can be up to 40 metres. The presence of gold is related to river erosion of the
Cordillera Oriental. Two main types of gold deposits can be found in the Madre de Dios region. The first is piedmont gold deposits directly related to the erosion of the eastern mountain range in Pliocene. The second type of deposits, which are the focus of this research, are those of the alluvial plain, among which two separate categories can be distinguished: the current deposits and the deposits of the alluvial plain. The current deposits are those located on riverbank beaches and river bottoms as a result of annual accumulation. The mineralization of gold in sediments ranges from 0.5 to $5 \mathrm{~g} / \mathrm{m}^{3}$. The gold deposits of the alluvial plain are the effect of long-term uninterrupted accumulation and gold mineralization and can be as much as $25 \mathrm{~g} / \mathrm{m}^{3}$. However, these gold-bearing layers are covered by a few metres of thick fluvial sediments (Lanckneus 1991).

\section{Methods}

The main focus of the experiments was to calculate indices based on remote sensing data that allow changes in the environment to be observed. The analysed data included two main images of the Madre de Dios region. The first was obtained by Landsat 7 on 30 August 2001 (ID: LE07 L1TP 0030692001083 0_20170203_01_T1); the second was obtained by Sentinel-2 on 24 July 2017 (ID: L1C_T19LCF_A010904_20170724T150005). During image selection, aspects such as the dry season and lack of clouds were taken into consideration. The first image was sensed by a Landsat mission a few years before the gold rush started in this particular part of the region; the latter one was obtained 10 years after the first mining activity (WRI 2018). For this study, an area of interest has been designated (Fig. 2), taking into account the places where illegal exploitation occurs. For more detailed figures, a smaller part of the area has been chosen. For the analysis presented below, the numbers in the formula of the given index denote the Sentinel-2 satellite band.

Normalized Difference Vegetation Index (NDVI)

Loss of tree cover can be seen on the raw, unprocessed images but to obtain accurate estimations, the NDVI ratio was calculated (Rouse 1973). The two images described in the previous section were compared, as is shown in Figure 3. Both of them were pre-processed by applying Top of Atmosphere correction and converted to Surface Reflectance using DOS-1; the images delivered by Sentinel-2 were also converted to SR. All 


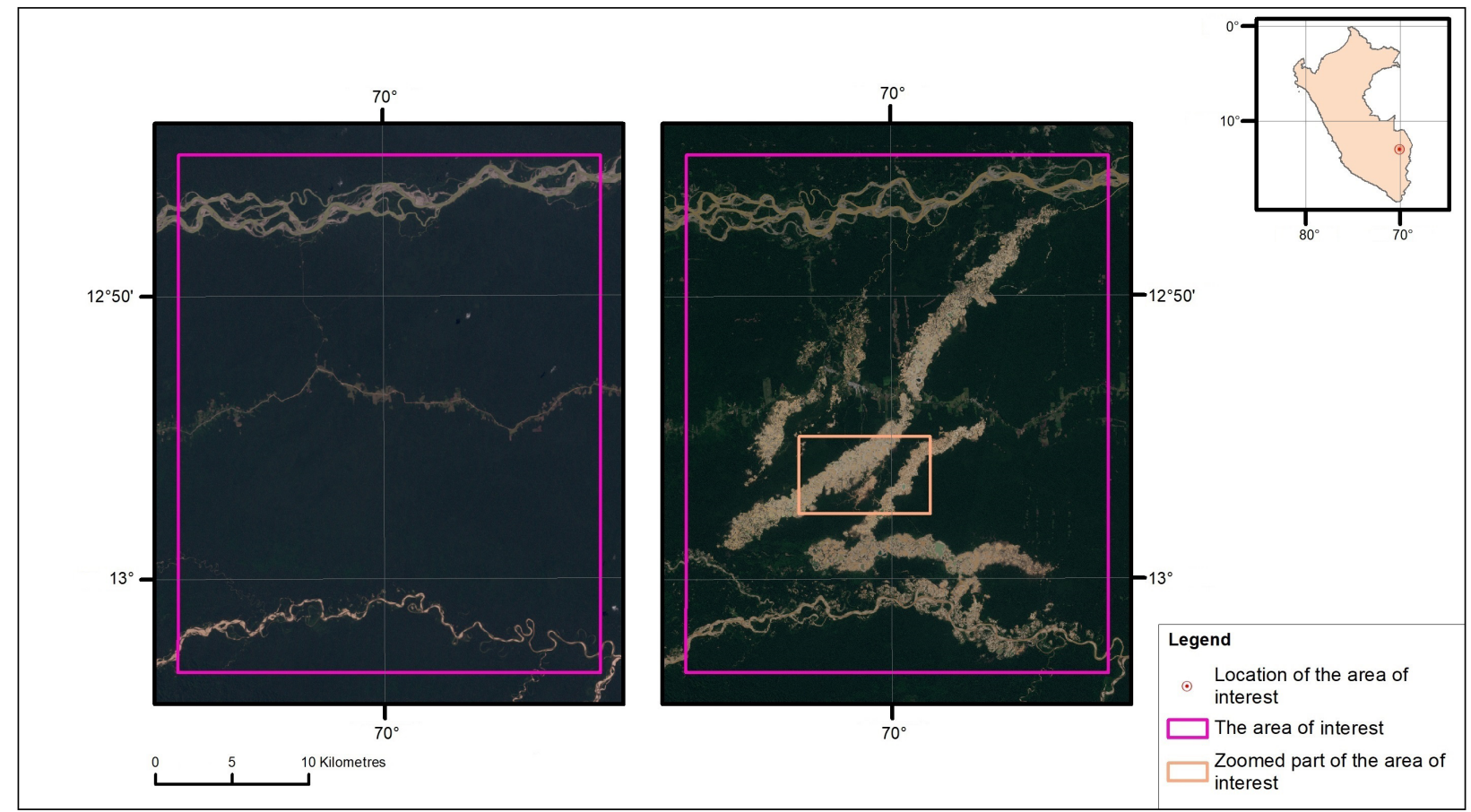

Figure 2. The appearance of the mine site revealed on satellite images. Left: 30 August 2001 (Landsat 7 imagery); right: 24 July 2017 (Sentinel-2 imagery)

Source: Own elaboration

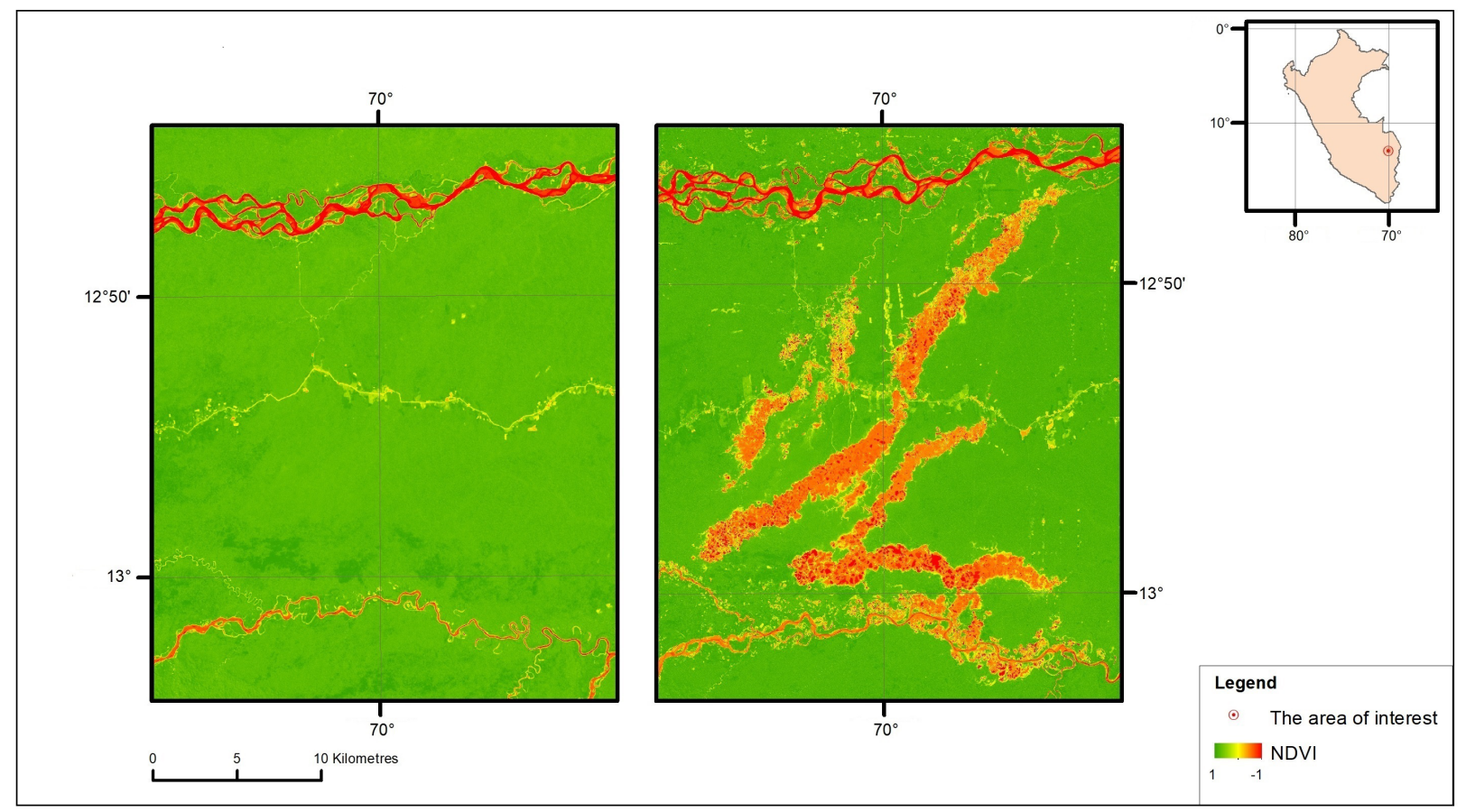

Figure 3. Vegetation loss visible through the NDVI ratio. Left: 30 August 2001 (Landsat 7 imagery); right: 24 July 2017 (Sentinel-2 imagery) Source: Own elaboration 


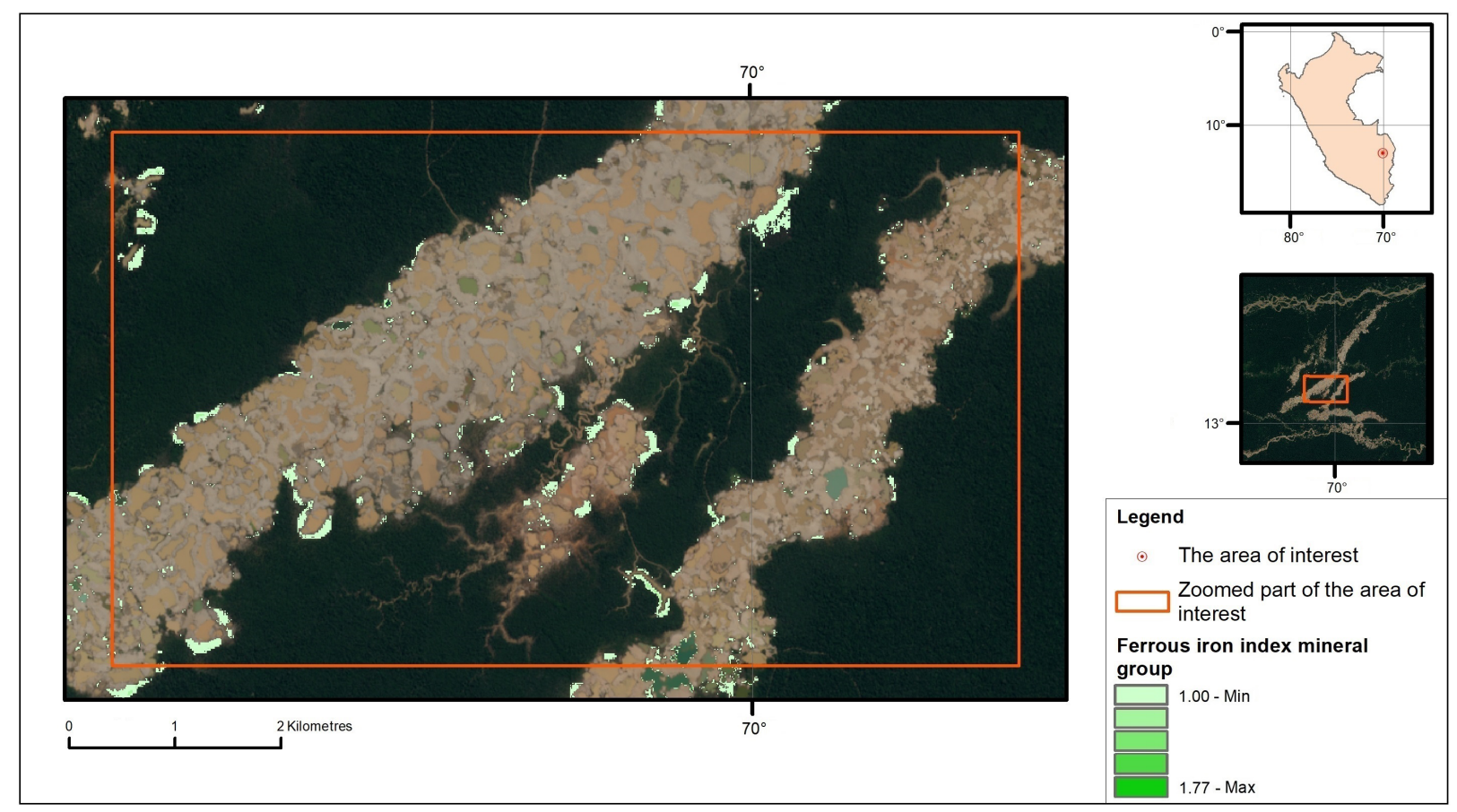

Figure 4. Zoomed part of the area of interest with ferrous iron index mineral group (ferrous iron - coarse-grained ferric iron - moist soils - fire ashes) highlighted

Source: Own elaboration

of the pre-processing was carried out using the Semi-Automatic Classification Plugin (QGIS) (Congedo 2016). The tree cover loss in the chosen test area was calculated as the difference in pixels representing vegetation between the 2001 image and the 2017 image.

In order to obtain more information, three main geology indices were calculated and analysed. This was to help interpret the current environmental chemistry and to predict the scale of damage. As previously described, the entire research area is located in the alluvial plain of Madre de Dios. Due to deforestation and the loss of the top layers (mostly silt, clay and sandy clay) (Lanckneus 1991), the basic environmental chemistry can be observed by analysing the mineral groups. The image delivered by Sentinel- 2 was used for this purpose. The three maps of indices described in the following subsections have been generated and post-processed as required. Many pixels highlighted, for example, as abundant in clay minerals were in the shadow of clouds, which could cause the wrong interpretation. As pixels with poor solar illumination may lead to false results (Knepper 2010) they were excluded from the analysis. With the help of the NDVI ratio, pixels representing water and vegetation have also been masked. The final step was to set thresholds for indices by leaving only the pixels with the highest values in order to limit the results to areas with the highest abundance of particular minerals (Rockwell 2013). For this, the distribution of mean and standard deviation has been analysed. To provide statistically representative values for all indices bootstrap analyses were performed. For figures 4-7 the darker the colour on the colour map scale, the higher the probability that a given mineral or mineral group is in greater abundance.

\section{Ferrous iron mineral group}

The ferrous iron mineral group was calculated as $(3+11) /$ $(4+8 a)(($ Green + SWIR) / (Red + Narrow NIR)) (Lupa \& Lesniak
2015). The ferrous iron ratio allows areas to be identified where iron in the +2 oxidation state is abundant (Rockwell 2013). This is helpful when tracking pyrite weathering as ferrous iron $\left(\mathrm{Fe}^{2+}\right)$ is produced when pyrite is exposed to water and atmospheric oxygen; with future access to atmospheric oxygen, it then oxidizes into ferric iron $\left(\mathrm{Fe}^{3+}\right)$ (Persson 2009). This ratio can also highlight areas where coarse-grained ferric iron, moist soils or fire ashes are present (Rockwell 2013). Due to the geology of the area in question, it can be expected that the ratio will highlight ferrous iron or moist soils. As described by Persson (2008), the weathering of minerals that results in the appearance of $\mathrm{Fe}^{2+}$ needs time. It is very likely, due to the fact that mining activity has only recently begun in the area in question, that the distinguished pixels (Fig. 4) are mostly related to wet soils. In comparison, the ratio at the Rio Huaypetue mine site (located about $50 \mathrm{~km}$ to the west) (Fig. 5 ), which has been operating much longer (at least since the nineties), presents much higher values.

\section{Minor ferric iron mineral group}

The minor ferric iron mineral group was calculated as (4/2) (Red / Blue) (Lupa \& Lesniak 2015). Minor ferric iron identifies areas where minerals like jarosite, goethite and hematite occur (Rockwell 2013). The first two can be considered as products of weathered pyrite minerals (Tutor et al. 2013) which appear in the later stages of weathering reactions (Persson 2008). It can be seen in Figure 6 that the ratio indications have highlighted the areas within ongoing mining operations.

\section{Clay-sulphate-mica-marble mineral group}

The clay-sulphate-mica-marble mineral group was calculated as (8a/4) (Narrow NIR / Red) (Lupa \& Lesniak 2015). The clay index shows the presence of many minerals from the clay-sulphate-mica-marble group (Rockwell 2013). Taking account of the geology of the alluvial plain of Madre de Dios, it can be 


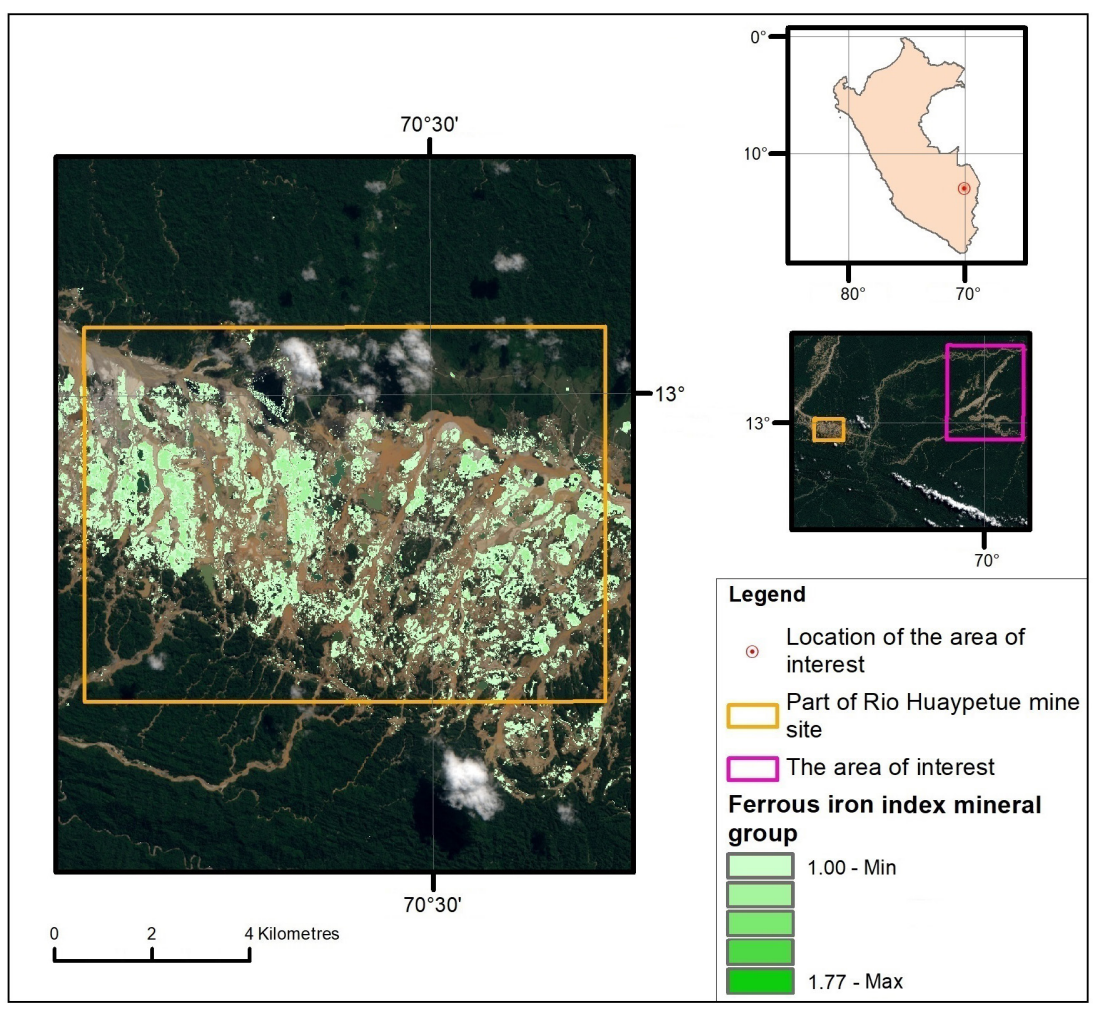

Figure 5. Zoomed part of the Rio Huaypetue mine site with ferrous iron index mineral group (ferrous iron - coarse-grained ferric iron - moist soils - fire ashes) highlighted

Source: Own elaboration

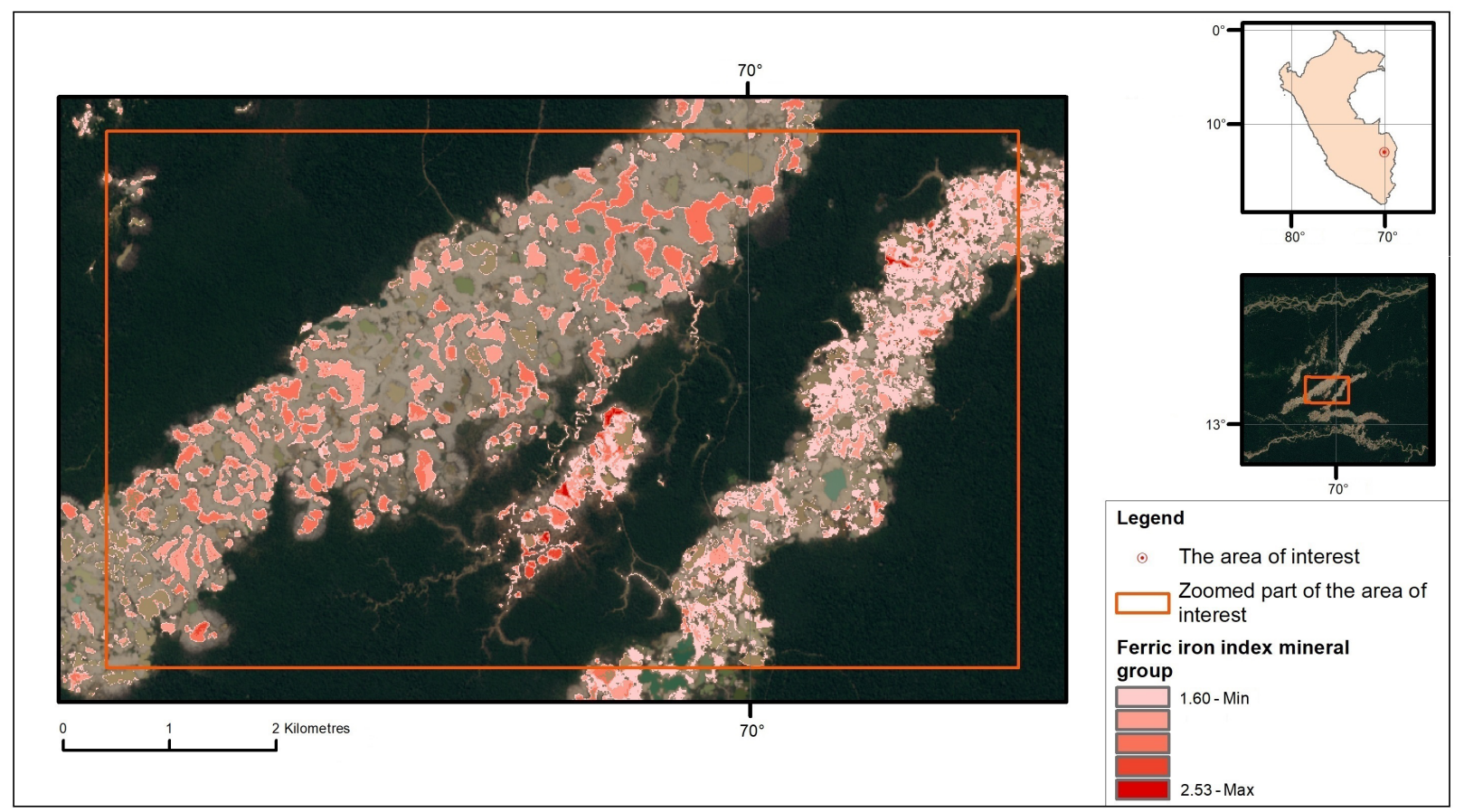

Figure 6. Zoomed part of the area of interest with ferric iron index mineral group (minor ferric iron) highlighted Source: Own elaboration 


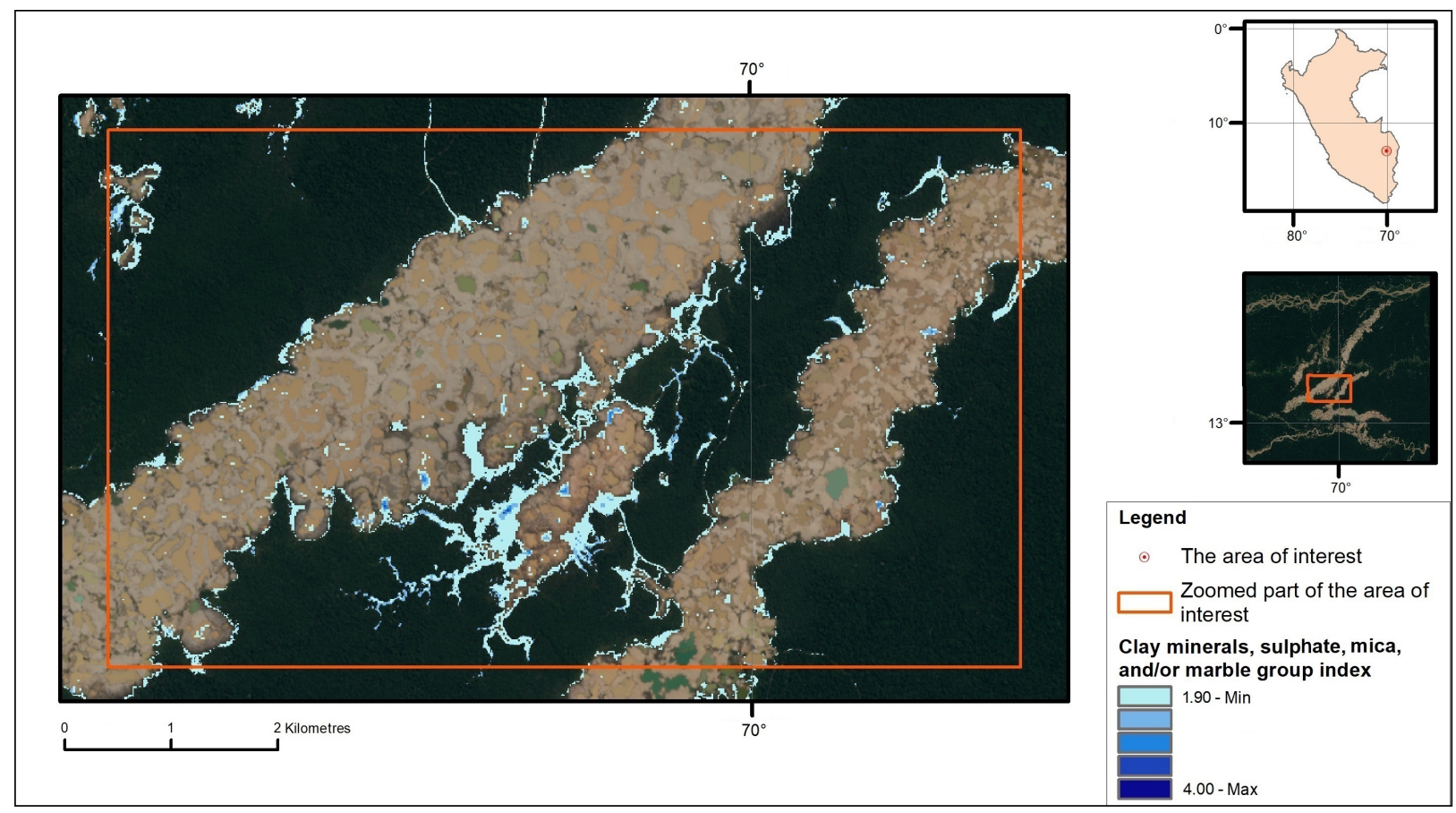

Figure 7. Zoomed part of the area of interest with clay-sulphate-mica-marble index mineral group (minor ferric iron) highlighted Source: Own elaboration

reasonably assumed that the ratio highlights are related to clay minerals and sulphates being a product of pyrite weathering (Fig. 7).

\section{Discussion}

Analyses of the obtained data can provide a variety of information that helps on a basic level to both understand the current situation at mine sites and state the risk of the propagation of pollution. This study confirms the usefulness of remote sensing in this case as illegal mining sites can be easily seen on the satellite images, as is shown in Figure 2; this suggests that remote sensing is an accurate tool for the detection of illegal activity in hard-to-reach areas.

Satellite images are considered to be one of the easiest ways to obtain data related to vegetation loss in remote areas such as the Amazon Rainforest. The tree cover loss analysis revealed significant changes in the amount of vegetation in this particular part of the region. For the area of interest $\left(930 \mathrm{~km}^{2}\right.$ in size) tree cover loss was estimated for roughly $147 \mathrm{~km}^{2}$ (about $17 \%$ of the total area) (Fig. 3). Nevertheless, it should be noted that some part of the loss in vegetation cover may also have been caused by factors other than mining (such as road construction or agriculture). Moreover, the fact that the data come from two different sensors (Landsat 7 and Sentinel-2) may also affect the results. Therefore, the quality of the research would be improved if harmonized data was used, such as those provided by the HLS project (Claverie et al. 2018).

The examination of the geology indices strongly suggests that the processes of weathering pyrite are in progress. The weathering of pyrite can lead to increased Acid Mine Drainage (AMD) and thus the risk of the release of acid into the waters of the Madre de Dios river and indirectly, into the Amazon River. The increasing levels of heavy metal pollution is an important problem associated with AMD (Lei et al. 2010). Furthermore, as described in the introduction, the area in question is also highly contaminated with mercury. The presence of clay minerals (Fig. 7), capable of binding metal ions and transporting them downstream, points to the likelihood of an increasing level of heavy metal contamination that is a real threat to local communities and to any life downstream on the Amazon River (Persson 2009). This process brings the risk of contamination with heavy metals, not only of mine sites but also of areas along the riverbanks. The results show a lack of minerals from the clay-sulphate-mica-marble group in central areas (and occupying a large part) of the mines, which has strengthened the view that bright tones of imagery are related to sands and gravel from which clay minerals have been washed out. This phenomenon is alarming as rebuilding the vegetation and the previous state of the forest in such areas can be very difficult. Moreover, it should be stressed that the results provided by the indicators for the area in question are mostly related to spectral answers from weathering minerals causing the response to be weaker than in the case of primary minerals. It can thus be reasonably assumed that the highlighted pixels are those that have significant indices values. It is plausible that this research has a number of limitations, including the resolution of the imagery, above all. The spatial resolution of the Landsat 7 data used is $30 \mathrm{~m}$ (ESA) and $10 \mathrm{~m}$ for Sentinel-2 data (ESA [3]), presenting mixed pixels, which can influence the analysis negatively. In perfect weather conditions, imagery can be obtained every five days (as this is the revisit time of Sentinel-2) (ESA [2]). However, this can be very limited due to weather conditions, especially during the rainy season when it is extremely hard to acquire cloudless imagery.

Finally, the spectral resolution of data is an important limitation of this study. A much more detailed analysis would be possible using hyperspectral data. It is not possible to track the presence of particular metals using the spectral resolution of either Landsat 7 or Sentinel-2 imagery. 


\section{Conclusion}

The aim of this research was to investigate the usage of satellite data to assess the state of the environment affected by illegal gold mining, using the example of the Madre de Dios region. It should be stressed that the area considered for this research needs special protection as it is one of the world's most precious regions. The scale of illegal mining in Madre de Dios is out of control and poses a real threat to this region of the world that is considered a natural treasure. Taken together, the results of this research suggest that satellite date can reveal the basic environmental condition of the chosen part of the Amazon Rainforest. Data acquired by Landsat and the Sentinel mission have been used for this study.

The NDVI ratio can be helpful for many tasks, including determining the boundaries of an illegal mine site and observing changes in its shape. Furthermore, tree loss is a real threat to the Amazon region and it needs to be monitored; this study found tree loss in the area in question to be at $17 \%$ over the years 2001-2017. Calculation and analysis of geological indices allow weathering processes and the leaching of clay minerals to be observed. The results suggest that the processes of weathering pyrite take place within the mine site, which may lead to further deterioration of the environment in this area. The same conclusion applies to the leaching of clay minerals, due to their impact on the transport of pollutants, and to the difficulties concerning the natural regeneration of vegetation within gravelly-sandy areas arising from mining activities. The calculations described can be performed quickly and simply using free-access data and open software.

Finally, limitations need to be considered, including spectral, time and spatial resolution of data. The results should be read with caution, taking the specifics of the indices into consideration, as well as the geology of the region. Despite this, it has been proven that remote sensing methods can provide satisfactory information about illegal mine sites. Information gathered during this research could support decision-makers in determining which areas require immediate protection and which are at risk of pollution; they can do this relatively quickly and with no additional cost. Moreover, the information collected could help in the planning of more detailed field research

\section{Acknowledgements}

This work has been partially financed by the funds of the Faculty of Geology, Geophysics and Environmental Solutions, AGH University of Science and Technology in Krakow.

\section{ORCID}

Katarzyna Adamek (iD https://orcid.org/0000-0003-2595-9296

Michał Lupa (1) https://orcid.org/0000-0002-4870-0298

Mateusz Zawadzki (iD https://orcid.org/0000-0002-2126-2822

\section{References}

Amazon Conservation Association 2014, Fact sheet: illegal gold mining in Madre de Dios, Peru. Available from: <http://www. amazonconservation.org/>. [10 December 2017].

Asner, GP \& Tupayachi, R 2017, 'Accelerated losses of protected forests from gold mining in the Peruvian Amazon', Environmental Research Letters. IOP Publishing, vol. 12, no.9.

Butler, R 2012, Environmental impact of mining in the rainforest. Available from: <https://rainforests.mongabay.com/>. [10 December 2017].

Claverie, M, Ju J, Masek, JG, Dungan, JL, Vermote, EF, Roger, J, Skakun, SV \& Justice, C 2018, 'The Harmonized Landsat and Sentinel-2 surface reflectance data set', Remote sensing of environment, Elsevier, vol. 219, pp. 145-161.

Congedo, L 2016, Semi-automatic classification plugin documentation Release, 4(0.1), 29. Available from: <https:// semiautomaticclassificationmanual.readthedocs.io/>. [10 December 2017].

ESA, eoPortal Directory. Available from: < https://earth.esa.int/ web/eoportal/satellite-missions///landsat-7>. [April 2020]

ESA [2], SENTINEL-2 - Missions - Sentinel Online. Available from: <https://sentinel.esa.int/web/sentinel/missions/ sentinel-2>. [12 September 2019].

ESA [3], Sentinel Online. Available from: <https://sentinel.esa. int/web/sentinel/missions/sentinel-2/instrument-payload/ resolution-and-swath>. [5 April 2020].

Heck, C 2014, 'La realidad de la minería ilegal en países amazónicos' ['The reality of illegal mining in Amazonian countries'], Sociedad Peruana de Derecho Ambiental.

INGEMMET, Mapa Geológico del departamento de Madre de Dios [Geological Map of the department of Madre de Dios], INGEMMET (Instituto Geológico Minero y Metalúrgico Lima), Peru.

Forest, J 2012, 'Rainforest biodiversity - the management challenges: Case study of the Tambopata Region, SouthEast Peru', Geofile Online for AQA, vol. 4, no. 2.
Kopačková V 2019, 'Mapping Acid Mine Drainage (AMD) and Acid Sulfate Soils Using Sentinel-2 Data', in IGARSS 20192019 IEEE International Geoscience and Remote Sensing Symposium. IEEE, pp. 5682-5685.

Knepper, D H 2010, 'Distribution of potential hydrothermally altered rocks in central Colorado derived from Landsat Thematic Mapper data: A geographic information system data set', A geographic information system data set: U.S. Geological Survey Open-File Report 2010-1076. Available from: <https://pubs.usgs.gov/of/2010/1076/downloads/ OF10-1076.pdf>. [10 December 2017].

Lanckneus, J 1991, 'Los placeres de Madre de Dios (SE Peru) [The deposits of Madre de Dios (SE Peru)]' in Gisements alluviaux d'or $=$ Alluvial gold placers $=$ Yacimientos aluviales de oro, eds. G Hérail \& M Fornari, ORSTOM, pp. 89-102.

Lei, L, Song, C, Xie, X, Li, Y \& Fei, W 2010, 'Acid mine drainage and heavy metal contamination in groundwater of metal sulfide mine at arid territory (BS mine, Western Australia).' Transactions of Nonferrous Metals Society of China, vol. 20, no. 8, pp. 1488-1493.

Lobo, F de L, Souza-Fliho, PWM, Novo, EML de M, Carlos, FM \& Barbosa, CCF 2018, 'Mapping mining areas in the brazilian amazon using msi/sentinel-2 imagery (2017)', Remote Sensing. Multidisciplinary Digital Publishing Institute, vol. 10, no. 8.

Lupa, M \& Lesniak, A 2015, 'New prospects for automated geological mapping with Sentinel-2 multispectral instrument' in 16th Czech - Polish workshop ON RECENT GEODYNAMICS OF THE SUDETY MTS. AND ADJACENT AREAS.

Olofsson, P, Holden, CE, Bullock, EL \& Woodcock, CE 2016, 'Time series analysis of satellite data reveals continuous deforestation of New England since the 1980s', Environmental Research Letters, vol. 11, no. 6, IOP Publishing. 
Persson, M 2009, Mining activity impact on fluvial sediments in the sw Amazon drainage basin, Peru, University of Gothenburg.

Rockwell, BW 2013, 'Automated mapping of mineral groups and green vegetation from Landsat Thematic Mapper imagery with an example from the San Juan Mountains, Colorado' US Geological Survey Scientific Investigations Map, vol. 3252.

Rouse, JW, Haas, RH, Schell, JA, \& Deering, DW 1973, Monitoring the vernal advancement and retrogradation (green wave effect) of natural vegetation, Progress Report.

Seifi, A, Hosseinjanizadeh, M, Ranjbar, H \& Honarmand, M 2019, 'Identification of acid mine drainage potential using sentinel 2a imagery and field data', Mine Water and the Environment. Springer, vol. 38, no. 4, pp. 707-717.

Swenson, JJ, Carter, CE, Domec, J \& Delgado, Cl 2011, 'Gold mining in the Peruvian Amazon: global prices, deforestation, and mercury imports' PloS one, vol. 6, no. 4.

Tutor, FV, Murciego, AM, Valle, PA, Ayuso, EÁ, Pascual, EP \& Sánchez, AG 2013, 'Weathering products of arsenopyrite and pyrite from El Bollo mine wastes (Salamanca, Spain) and their environmental hazards' Revista De La Sociedad Española De Mineralogía, vol. 17, pp. 111-112.

UNODC 2016, Colombia. Explotación de oro de aluvión. Evidencias a partir de percepción remota [Colombia. Exploitation of alluvium gold. Remote sensing evidences], United Nations Office on Drugs and Crime. Available from: $<$ https://www.unodc.org/>. [10 December 2019].

Viljo, K, Hilkka, A, Francis, C, Eija, H, Jukka, L \& Maarit, M 2003, Guidelines for Image Processing procedures and algorithms for mining related contamination and impact detection from airborne imaging spectroscopy. Available from: <http://tupa. gtk.fi/>. [10 December 2019].

Viña, A, Echavarria, FR \& Rundquist, DC 2004, 'Satellite change detection analysis of deforestation rates and patterns along the Colombia-Ecuador border', AMBIO: A Journal of the Human Environment. BioOne, vol. 33, no. 3, pp. 118-125.

Wagner, L 2016, Organized crime and illegally mined gold in Latin America. Available from: <https://globalinitiative. net/organized-crime-and-illegally-mined-gold-in-latinamerica/>. [10 December 2019].

World Resource Institute 2018, Global forest watch. Available from:<http://www.globalforestwatch.org/map/>. [5 September 2019].

Zagajewski, B 2000, 'Remote sensing measurements of lead concentration in plants' Miscellanea Geographica, vol. 9, no. 1, pp. 267-282. 